\title{
Failure Characteristics Induced by Unloading Disturbance and Corresponding Mechanical Mechanism of the Coal Seam Floor in Deep Mining
}

\author{
Jiazhuo Li ${ }^{1,2, *}$, Guangxiang Xie ${ }^{1}$, and Lei Wang ${ }^{1}$ \\ ${ }^{l}$ Anhui Province Key Laboratory of Mining Response and Disaster Prevention, and Control in Deep Coal Mine, Anhui University \\ of Science and Technology, Huainan, Anhui 232001, China \\ 2 School of Resource and Safety Engineering, Anhui University of Science and Technology, Huainan, Anhui 232001, China \\ * Correspondence: 2015019@aust.edu.cn; Tel.: +86-0554-6671160
}

\begin{abstract}
Failure characteristics induced by unloading disturbance and the corresponding mechanical mechanism of the coal seam floor are important theoretical bases for water-bursting prevention from the floor of the coal seam and rock burst alarm in deep mining. However, the existing two-dimensional ground-pressure-control theory based on shallow mining cannot sufficiently guide deep-mining practices. In this study, the redistribution of mining-induced stress field in rocks surrounding the longwall face and mechanical behaviors of strata in deep mining are investigated through a combination of numerical simulation, physical simulation, and field measurement. Results demonstrate that mining-induced stress fields in the floor of the longwall face differ in space and time. Vertical stress unloading from top to bottom of the floor and horizontal stress unloading are relatively low. A concentration zone of high horizontal stress exists at stope boundaries. The critical yield load of rock stratum in the floor is determined through thin plate yield theory. Under the combined effect of concentrated high horizontal and vertical resilience stresses, strata in the floor fracture from seam to seam if the load increases to the minimum critical buckling value. Fractured strata slide along the fracture surface, which leads to floor heave. The stope floor shows evident time-delay progressive failure characteristics. The stress shell in the stope floor in deep mining is found to be a sensitive mechanical parameter that produces three-dimensional ground-pressure behavior in the floor. This ground-pressure behavior in the stope floor is controlled by the existence of the corresponding stress shell and effects induced by its space-time evolution. This study provides theoretical basis for the dynamic control of a hazard-inducing environment in engineering and minimizing or altering disaster-occurrence conditions during the construction engineering of the coal seam floor.
\end{abstract}

Keywords: deep mining; coal seam floor; unloading disturbance; space-time difference; stress shell; mechanical mechanism 


\section{Introduction}

In underground coal mining, particularly those high-strength caving mechanized longwall panels in deep coal mine, strong ground-pressure behavior will develop in the coal seam floor. Studying the development of ground-pressure behavior in the coal seam floor is an important theoretical basis for impact prevention of rock burst, coordinated mining of high gas coal seam group, surrounding rock control in roadway influenced by overhead mining, and coal mining above confined aquifers during the construction engineering of the coal seam floor. In 1966, Cook et al. (1966) established the calculation method of energy release rate during excavation of deep rock mass. Subsequently, Walsh et al. (1977) systematically and comprehensively analyzed variation of the surrounding rocks during deep rock excavation and described the secondary equilibrium process of the surrounding rock energy caused by excavation unloading. Hoek et al. (1997) discovered that fracture characteristics of rock mass were related to the stress state, which was manifested as brittle failure under low-stress state, but will also show brittle or ductile failure under high-stress state. Aubertin et al. (2000) believed that rock mass will represent shrinking, dilatancy, and even tensile fractures under excavation unloading conditions. Li (1999) divided the coal seam floor into the fracture, protection, and confined water intrusion zones. Wang and Liu (1994) proposed "zero damage" and "in-situ tension crack." Yuan (2006) deemed that heave fissure and heave deformation zones on the underlying rock strata after the protective coal seam was mined were observed. Qian et al. (1995) proposed the critical layer in the floor and believed that fracture of this critical layer is determined by the structural morphology after rock mass fracture in the stope floor. Jiang et al. (1999) gained the stress distribution of the stope floor by using the finite element method and acquired activity characteristics of the rock strata in the stope floor during mining activities. Wang et al. (2002) pointed out that rock stratum failure in the stope floor occurs in the goaf. They reported that tensile failure is the major failure mode and the maximum failure depth at floor is determined by macroscopic mining technological parameters and geological conditions. Wang et al. (2013) constructed a space semi-infinite body model with comprehensive considerations to stope strike and inclined force characteristics. He stated that stress unloading and concentration would transmit to deep positions of floor, thus influencing the failure depth and scope of the floor. Zhang et al. (2015) zoned the stope floor according to redistribution of vertical stress on the floor of the longwall panel and discussed fissure development features in different zones. Zhu et al. (2009) calculated the influence depth of mining of "threesoft" coal seam floor by the strain method. Wu et al. (2003) gained the failure depth of No. 7 coal seam floor in Zhuzhuang Coal Mine through in-situ water injection test. Feng et al. (2015) solved the dual integral equation by using Fourier integral transformation and gained the analytical expression of stress and displacement fields in the stope 
floor.

With considerations to specific in-situ engineering problems, previous studies focused on fracture depth of stope floor rock strata or mining-induced stress field. The maximum fracture depth and mining-induced stress field distribution characteristics of stope floor rock strata after coal seam recovery were disclosed. In fact, the development of mining pressure in the stope surrounding rocks is controlled by the existence of three-dimensional (3D) stress field and effects brought by its changes (Xie et al. 2013; Li 2015). Therefore, dynamic evolution of the 3D mining-induced stress field is the basis to study the activity of the stope floor. Key attentions shall be paid to 3D spatial features of mining-induced stress field, failure zone and displacement field in the stope floor as well as their variation over time, and internal correlations. In this study, these 3D spatial characteristics were discussed systematically with a comprehensive research method.

\section{Geological background and research program of the engineering}

\section{Geological and mining conditions}

The fully mechanized mining method was utilized in the 66207 panel in Xinzhuangzi Coal Mine in Huainan, China. The mining height was $2.7 \mathrm{~m}$. The ground elevation was $+18.0-20.5 \mathrm{~m}$ and a panel elevation of -721-793 m. The panel layout was $132 \mathrm{~m}(\mathrm{~W}) \times 533 \mathrm{~m}(\mathrm{~L})$, with $1.40 \mathrm{t} / \mathrm{m}^{3}$ as the volume weight of coal body and $17^{\circ}$ as the dip angle of the coal seam.

The coal of fully mechanized longwall mining 66207 panel was soft, and the immediate roof was the sandy mudstone, which had an average thickness of $5.0 \mathrm{~m}$. The main roof was the fine sandstone and with the average thickness of $9.1 \mathrm{~m}$. The immediate floor was the mudstone with the thickness of $1.3 \mathrm{~m}$. The hard floor was formed by light-gray fine sandstone, accompanied with few fractures, which was about $10.0 \mathrm{~m}$.

\subsection{Numerical simulation}

The 3D calculation model of 66207 panel was established through the numerical simulation software FLAC3D, which is shown in Fig. 1. The model with slope angle of $17^{\circ}$ was built with dimensions of $550 \mathrm{~m}(\mathrm{~L}) \times 420 \mathrm{~m}(\mathrm{~W}) \times 423.84 \mathrm{~m}(\mathrm{H})$, covering a total of 257,950 units and 271,144 nodes. The mechanical parameters of the rock mass were introduced in the previous studies $(\mathrm{Li}$ 2015). A total of $12.9 \mathrm{MPa}$ vertical stress were applied at the upper boundary of the model to simulate overburden; the at-rest earth pressure coefficient was 1; and the surrounding boundaries of the model restrict horizontal displacement and the bottom boundary restricted the vertical displacement. The upper boundary was free. Static force problem and non-inertial static problem were solved using the kinematic equation and mechanical attenuating method, aiming to reproduce the progressive movement and complete failure morphology of the stope surrounding rocks. The gangue in the goaf was used as the volume hardening model. 


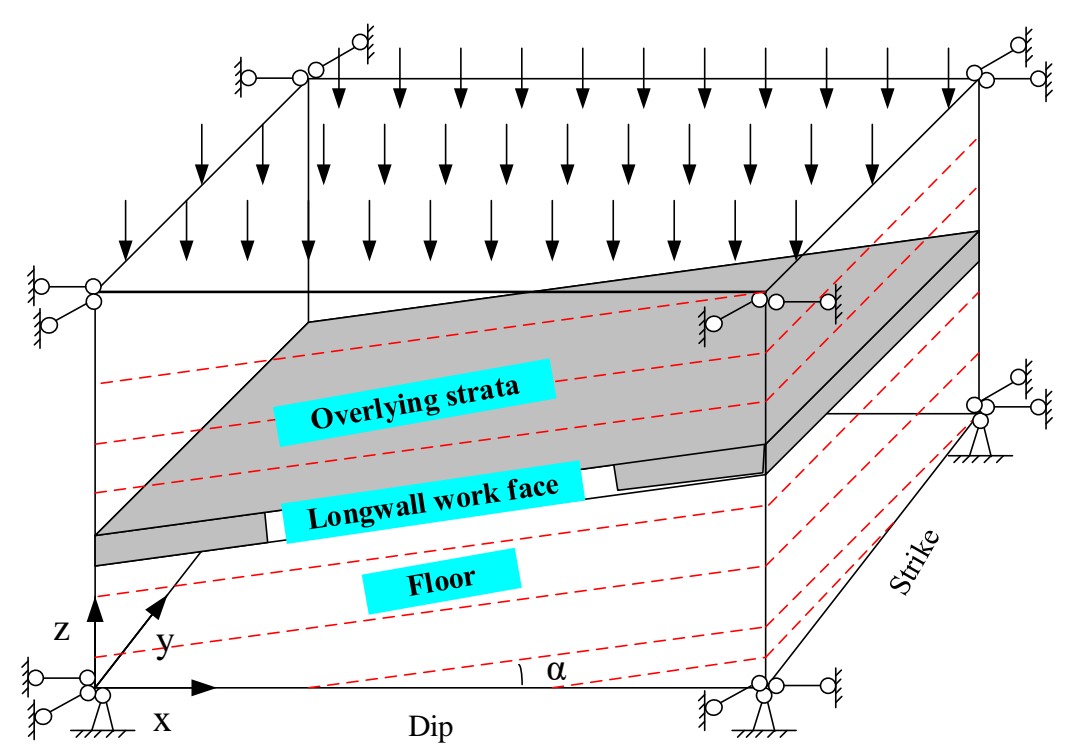

Fig. 1. Three-dimensional numerical calculation model

\subsection{Simulation program of similar materials}

(1) Test contents.

a. The vertical stress in the surrounding rocks of the stope floor changed as the 66207 panel advances.

b. The vertical displacement of the rock strata in the coal seam floor changed as the 66207 panel advances.

c. The macroscopic fracture phenomenon of the stope surrounding rocks was developed as the 66207 panel advances.

(2) Test goals.

a. Monitor changes of vertical stress in the stope surrounding rocks as the 66207 panel advances, and disclose the evolution of mining-induced stress field in the stope floor and its internal relationship with the movement of the overlying strata.

b. Monitor displacement changes of stope floor rock strata as the 66207 panel advances, and further disclose displacement field characteristics of the coal seam floor during mining activities as well as the movement laws of strata in the stope floor during overlying fracture and collapse.

(3) Model selection and model boundary determination.

The plane stress similarity model in the National Key Laboratory of Coal Resource and Safety Mining (China University of Mining and Technology (Beijing)) was selected as the experimental table for similar material simulation. The actual size of the experimental table was $420 \mathrm{~cm}(\mathrm{~L}) \times 200$ $\mathrm{cm}(\mathrm{H}) \times 25 \mathrm{~cm}(\mathrm{~W})$. According to occurrence situation of the coal seam on the 66207 panel, the paved model size was $420 \mathrm{~cm}(\mathrm{~L}) \times 170 \mathrm{~cm}(\mathrm{H}) \times 25 \mathrm{~cm}(\mathrm{~W})$. In this experiment, the advancing distance of the strike was $200 \mathrm{~cm}$. The left and right boundaries of the model were $110 \mathrm{~cm}$ away 
from the setup entry and terminal mining line of the 66207 panel.

(4) Determination of the model similarity ratio.

According to experimental goal and equipment, the geometric similarity constant was $C_{l}=1 / 100$. The overlying rock strata were replaced by artificial pressure application. The volume-weight similarity constant was expressed as $C_{\gamma}=1 / 1.67$, stress similarity constant as $C_{\sigma}=C_{\gamma} \times C_{l}=1 / 1.67 \times 1 / 100=1 / 167$, and time similarity constant as $C_{t}=\sqrt{C_{l}}=\sqrt{1 / 100}=1 / 10$. The actual daily advancing distance of the 66207 panel was $8 \mathrm{~m}$. In this experiment, the advancing distance every $2 \mathrm{~h}$ was set to $8 \mathrm{~cm}$.

(5) Similar materials and mixing ratios.

Material consumptions in different layers were calculated by as follows:

$G=l \times b \times h \times \gamma_{\mathrm{p}}$,

where $G$ is the total weight of layered material in the model, $b$ is the model width, $l$ is the model length, $h$ is the thickness of simulated layers, and $\gamma_{p}$ is the volume weight of simulated strata.

(6) Loading mode of the overlying rocks.

Limited by the actual size of the similarity simulation table, simulating from the panel to the surface was impossible. The weight of the overlying rocks which was not simulated in the model has to be replaced through loading. The gravity compensation load which had to be applied in the model was as follows:

$$
q_{m 1}=C_{\gamma} \times C_{l} \times \gamma_{p} \times\left(H-H_{m}\right)=7.166 \mathrm{t} / \mathrm{m}^{2},
$$

where $\gamma_{p}$ is the average volume weight of the overlying strata, which was determined using 2500 $\mathrm{kg} / \mathrm{m}^{3}$ as the mean; $H$ is the thickness of the rock strata from the surface to the coal seam roof, which is equal to the buried depth of the coal seam $(570 \mathrm{~m})$; and $H_{m}$ is the thickness of the rock strata above the immediate roof, which is $91.32 \mathrm{~m}$ in this study.

Considering the cross-section area of the simulation table, the load which has to be applied by the lever loading system above the model is $\mathrm{G}=7.166 \times 4.2 \times 0.25=7.52$ (tons).

\subsection{Field measurement}

Field observation sites were set in the tailentry of the 66207 panel, the underlying transportation cross-cut of No. 1 coal, and the roadway in the coal seam floor of 66206 panel (Fig. 2). Two observation stations were set (Fig. 3). Specifically, the observation station A was set in the tail entry of the 66207 panel, where four stress meters (KSE-II-1) were installed at the interval of $2 \mathrm{~m}$ and 2 multipoint convergence meters (KDW-1). The $4 \#$ stress meter at $2 \mathrm{~m}$ in front of the multipoint convergence meter was a bedding hole (depth $=9 \mathrm{~m}$ ), and the stress meter at the observation station 
A was $100 \mathrm{~m}$ in front of the 66207 panel. The observation station B was set in the roadway in the coal seam floor of 66206 panel and the underlying transportation cross-cut of No. 1 coal. The purpose of the setup was to study the 3D spatial distribution of stress in the floor strata and development law of surrounding rock fractures on the 66207 panel.

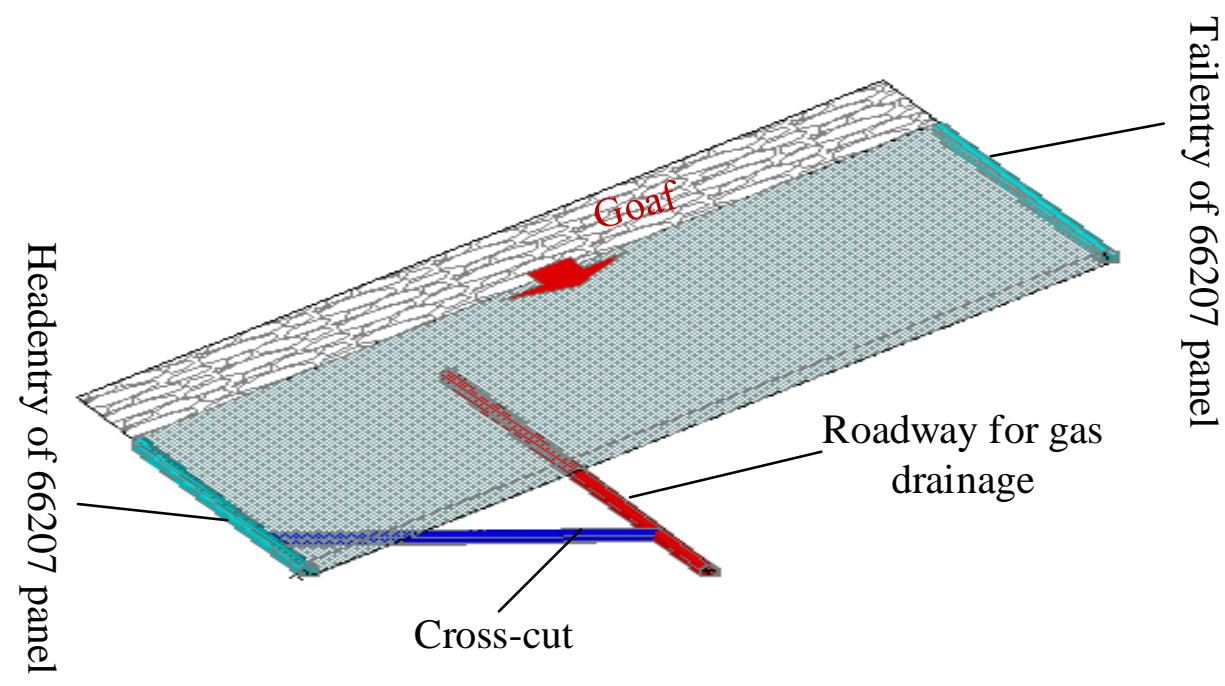

Fig. 2 Space horizon of roadway layout

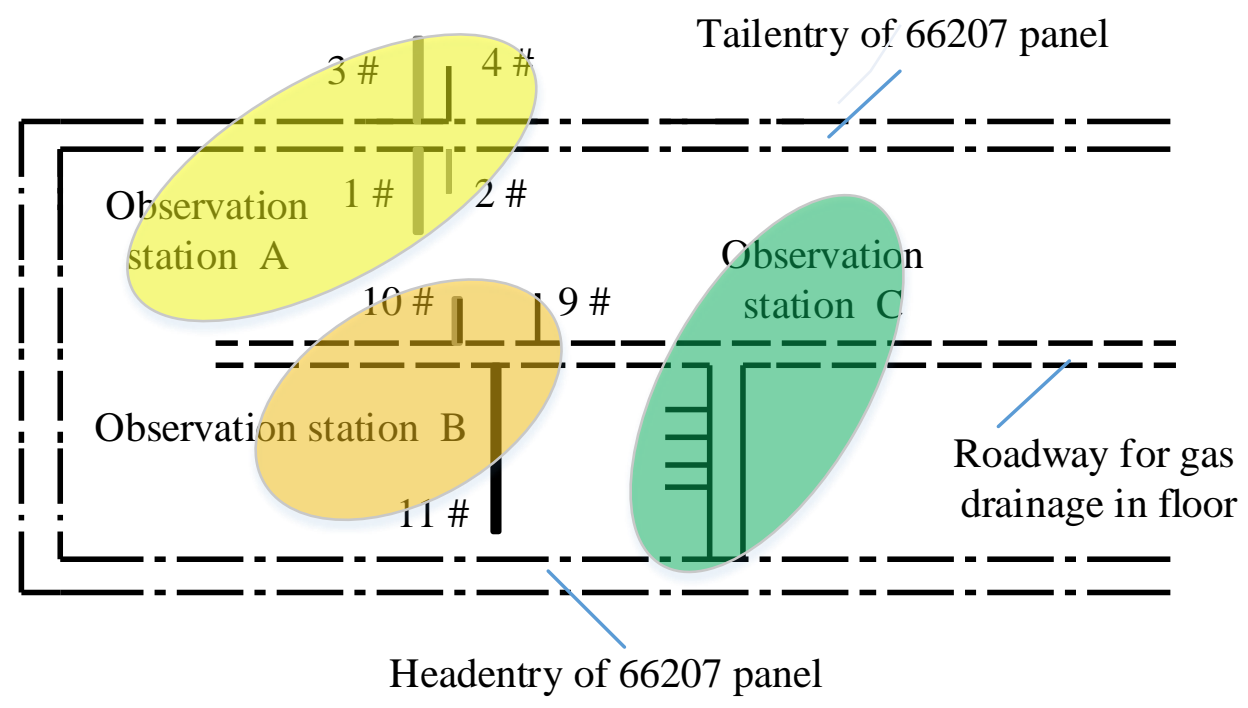

Fig. 3 Layout of stress meter borehole and peephole

\section{Plastic buckling fracture mechanism of the stope floor}

Under the squeezing effect of high ground stress, the deep coal seam floor rocks carry abundant elastic potential energy and gravitational potential energy. The mining activity induces changes of the mechanical state of the stope surrounding rocks and unloading of stope floor rocks toward the free face. This phenomenon is initially manifested by resilience, dilatation, and rheology of the rock strata and, finally, causes top-down buckling fracture of the stope floor and generates crossing macroscopic damage fracture faces.

\subsection{Mechanical mechanism of plastic buckling failure of the stope floor}


The thickness of the stope floor rock strata was far smaller than the dip length and advancing distance of the panel. Therefore, the stope floor rock strata can be viewed as the sheet surrounded by non-mined coal bodies in the stope (Sun et al. 2014). The movable abutment pressure in front of the coal face is higher than the lateral fixed abutment pressure of the coal seam. After the deep coal seam exploitation, the floor rock strata in a certain range in front of the coal face have developed plastic failure in advance. The existence of this plastic zone interrupted the connection between the stope floor and stress zone of primary rocks. Therefore, the deep stope floor rock strata can be viewed simply as a supporting rectangular plate under the collaborative effect of uniformly distributed horizontal and uniformly distributed in-plane forces. Let the advancing distance of the working face be $a$ and the dip length be $b$. The horizontal squeezing stress is $P_{x}$ and the tensile stress produced by vertical resilience is $q_{0}$ (Fig. 4).

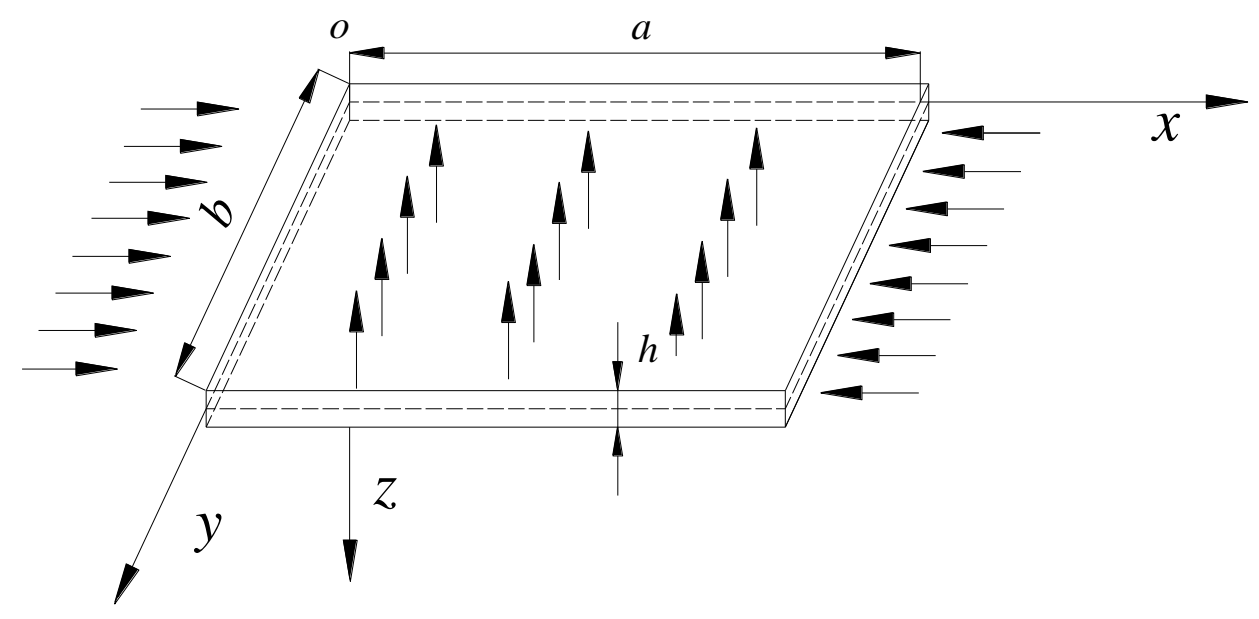

(a)

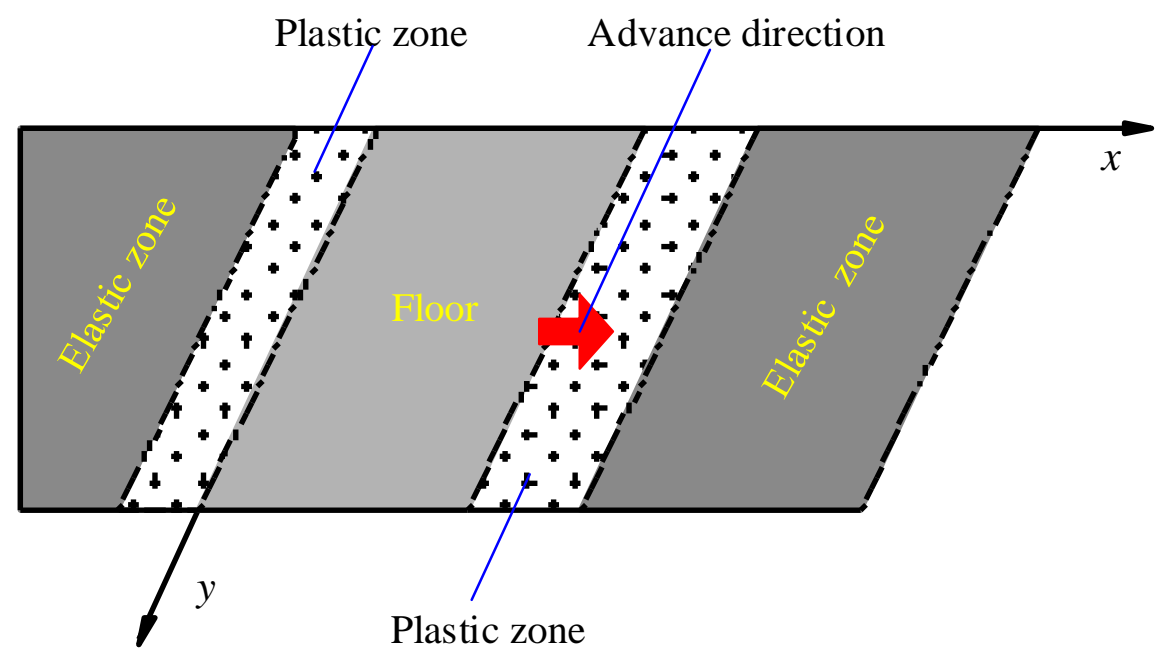

(b)

Fig. 4 Models of simply supporting structures at two sides of the stope floor under the effect of horizontal squeezing stress and uniformly distributed in-plane forces 
The differential equation of the elastic surface under the collaborative effect of horizontal and in-plane forces of the sheet (He et al. 2017) is expressed as follows:

$$
D \nabla^{4} w-P_{x} \frac{\partial^{2} w}{\partial x^{2}}=q_{0}
$$

The Navier solution method of horizontal load under the effect of $q_{0}$ was applied. The twofold trigonometric series of deflection $w$ and uniformly distributed horizontal load are as follows:

$$
\begin{gathered}
w=\sum_{m} \sum_{n} A_{m n} \sin \frac{m \pi x}{a} \sin \frac{n \pi y}{b}, \\
q_{0}=\sum_{m} \sum_{n} C_{m n} \sin \frac{m \pi x}{a} \sin \frac{n \pi y}{b},
\end{gathered}
$$

where $C_{m n}=\frac{16 q_{0}}{\pi^{2} m n},(m, n=1,3,5,7, \ldots, \infty)$.

Combining Equation (6) into Equation (5) and substituting the solved Equations (5) and (4) into Equation (3) enables the coefficient $A_{m n}$ at the solving point ( $w$ ) to be solved.

$$
w=\frac{16 \mathrm{q}_{0}}{\pi^{2} D} \sum_{m} \sum_{n} \frac{1}{m n\left[\left(\frac{m^{2}}{a^{2}}+\frac{n^{2}}{b^{2}}\right)^{2}+\frac{P_{\mathrm{x}} m^{2}}{\pi^{2} a^{2} D}\right]} \bullet \sin \frac{m \pi \mathrm{x}}{a} \sin \frac{\mathrm{n} \pi \mathrm{y}}{b} \quad(m, n=1,3,5,7, \ldots, \infty)
$$

where $m$ and $n$ are half-wave numbers at the bending of the sheet, $D$ is the extensional rigidity of the sheet, $D=\frac{E h^{3}}{12\left(1-\mu^{2}\right)}, E$ is the elasticity modulus, and $\mu$ is the Poisson's ratio of stope floor strata.

The number of terms in the composite trigonometric function is $m=n=1$. The minimum critical yield load can be calculated as follows:

$$
P_{\mathrm{x}}=\pi^{2} \mathrm{a}^{2} D\left(\frac{1}{\mathrm{a}^{2}}+\frac{1}{\mathrm{~b}^{2}}\right)^{2} .
$$

The minimum critical yield load $P_{\mathrm{x}}$ is related to the flexural rigidity and thickness of the rock strata as well as the advancing distance of the panel. In the long-term process of deep coal seam sedimentation, integrity of the lamellar structure with joint fissures was destroyed, accompanied with microcracks or soft rock strata in the local zones. The stratum thickness ranges from dozens of centimeters to several meters. The dip length $(b)$ of the fully mechanized longwall 66207 panel in Xinzhuangzi Coal Mine was $132 \mathrm{~m}$ and the maximum strike length $(a)$ was $132 \mathrm{~m}$. The thickness $(h)$ of the floor rock strata was $0-1.7 \mathrm{~m}$, elasticity model $(E)$ was $0.875 \times 10^{4}-2.54 \times 10^{4}$, and Poisson's ratio $(\mu)$ was $0.26-0.32$. Therefore, the minimum critical yield load $\left(P_{\mathrm{x}}\right)$ of the stope floor rock strata was $32.95 \mathrm{MPa}$.

\subsection{Mechanical mechanism of floor heave caused by slippage and diastrophism}


The stope floor resisted high stress around the stope surrounding rocks through strains, when the strain energy which is accumulated in strata exceeds the ultimate strain energy, stratum fracture at the cost of high elastic energy, and gravitational potential energy. After buckling the fracture of stope floor rock strata, high stress gradually migrates to deep positions, further resulting in successive top-down buckling failures of the rock strata. The fracture faces expand, connect, and concentrate which form abundant macroscopic failure surfaces. Facing with high horizontal squeezing stress and vertical resilience, the ruptured rock strata slid along the fracture surface and generate heaves (Fig. 5). The external load which is caused by rock stratum movement of the stope floor was inadequate to cause buckling failure.

The gravity of the overlying strata was transmitted to non-mined rock mass surrounding the panel through the stress shell after the coal seam is mined, which caused stress concentration on the coal face (Fig. 5). Stress concentration on the coal face further propagated toward the underlying strata and formed a high pressure zone (Zone I). The soft strata in the pressure stress zone within a certain depth initially developed plastic buckling and dilatation. The dilatation expansion and secondary horizontal stress on the stope surrounding rocks together formed the horizontal squeezing stress (Zone II). The horizontal squeezing stress acted on the strata with higher flexural rigidity. The expansion stress $\left(q_{0}\right)$ which was generated by the release of high elastic energy accumulated in the underlying strata intensified the failure degree. After reaching the critical buckling load of the strata, the delayed panel developed buckling failure at a certain distance. Meanwhile, the ruptured rock strata moved toward the goaf along the fracture surface due to the combined effect of horizontal squeezing pressure and vertical expansion, resulting in heave formation (Zone III)

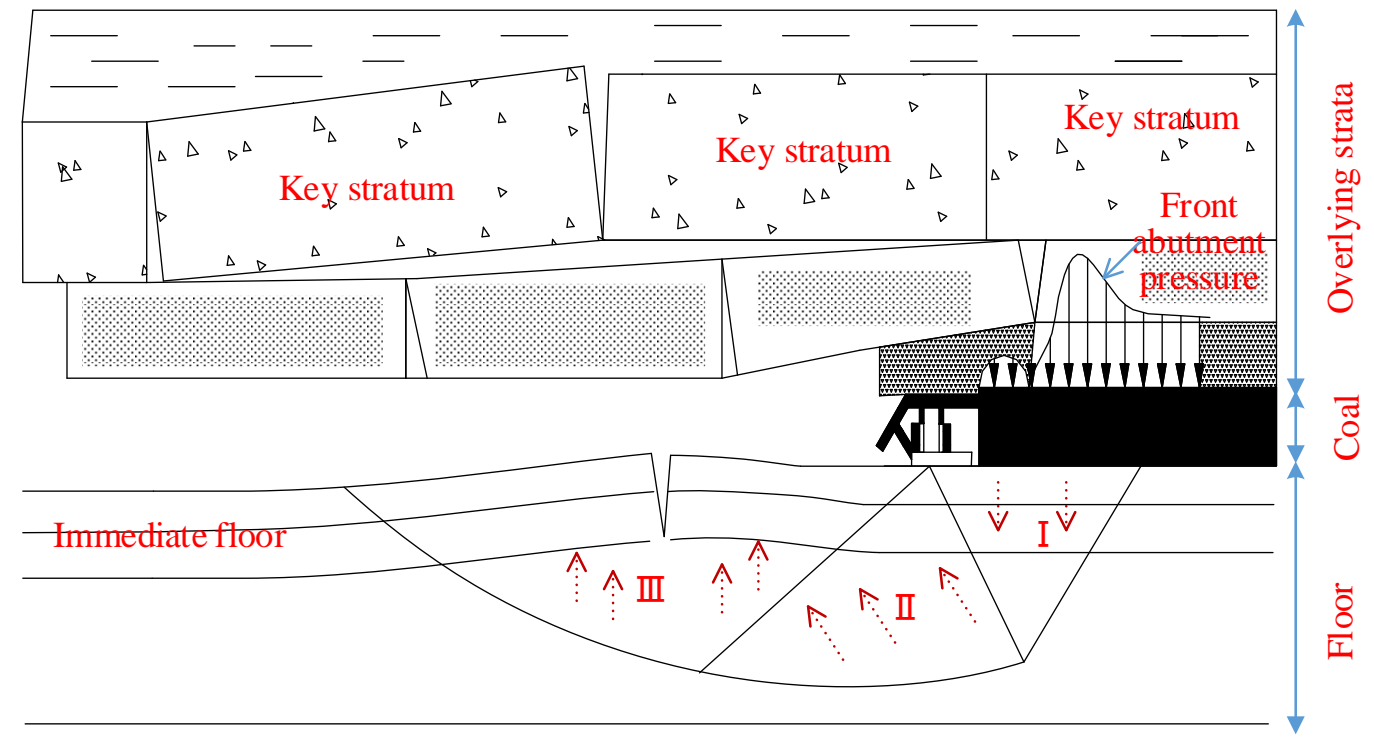

Zone I, pressure stress; Zone II, horizontal squeezing and expansion stress; Zone III, expansion

Fig. 5 The mechanical response model of slippage and diastrophism of the coal seam floor 


\section{Stress disturbance characteristics of unloading response of the coal seam floor}

The 3D stress field in the surrounding rocks of the stope floor regulated continuously after the coal seam is mined. A high-stress beam in the local areas of the surrounding rocks of the stope floor was observed, which formed the stress shell of the stope floor with thick walls (Li 2015; Xie et al 2018) (Fig. 6). The stress shell of the stope floor is the main concentrated force of roof stratum transfer and unloading-induced expansion of the floor and is a kind of mechanical effect of self-adjusting and stress route deviation for the surrounding rocks at the stope floor to resist heterogeneous deformation. In the stage of intensifying stress concentration and depth growth of the stress shell, the maximum principal stress of the surrounding rock stress shell declined.

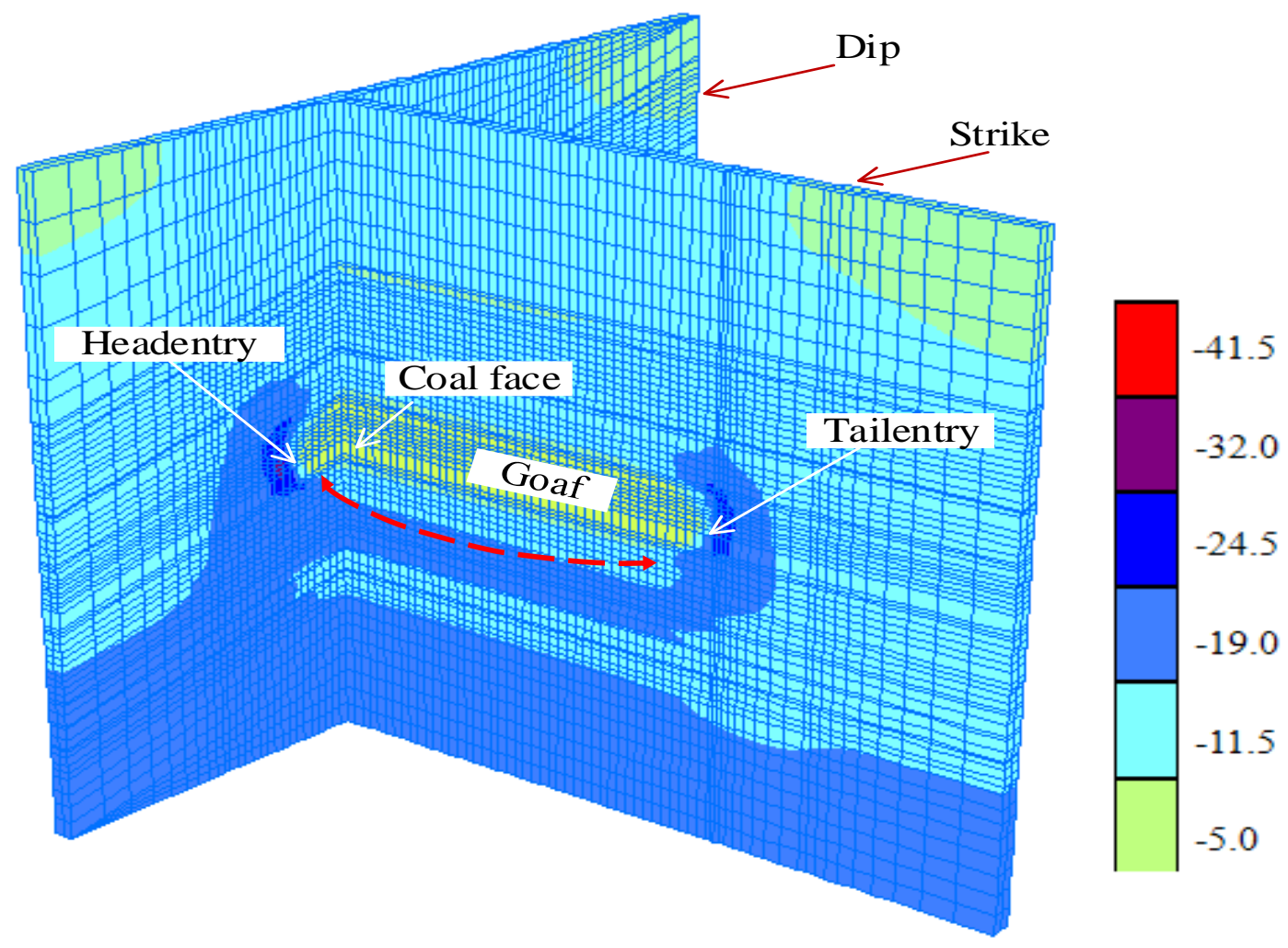

Fig. 6 Principal stress nephogram of the surrounding rock

Fig. 7 shows the stress distribution of the hard floor rock strata. Fig. 8 shows the complete redistribution layout of the mining-induced stress in the stope floor. Influenced by concentration and deflection of the maximum principal stress in the surrounding rocks of the stope floor, the underlying vertical stress $\left(\sigma_{z}\right)$ in front of the coal face and setup entry was higher than the primary rock stress. The stress concentration factor is 1.7 and decreases sharply beneath the goaf to $22 \%$ of the primary rock stress. The horizontal stress did not represent fierce unloading phenomenon and was maintained at a high level. Particularly, a high horizontal stress concentration zone close to the goaf existed. The maximum difference $\left(\sigma_{z}\right)$ between the horizontal $\left(\sigma_{y}\right)$ and vertical stress is $37.4 \mathrm{MPa}$, indicating the 
abnormal phenomenon of stress redistribution in the floor. The maximum horizontal stress $\left(\sigma_{y}\right)$ in the hard floor was 46.2 MPa, which was higher than the critical buckling load $P_{\mathrm{x}}$. Therefore, the hard floor developed buckling fracture. The hard floor initially fractured along the outer ring of the stope floor and, then, produced fracture surface parallel to the working face and rock beams which were mutually articulated and formed.

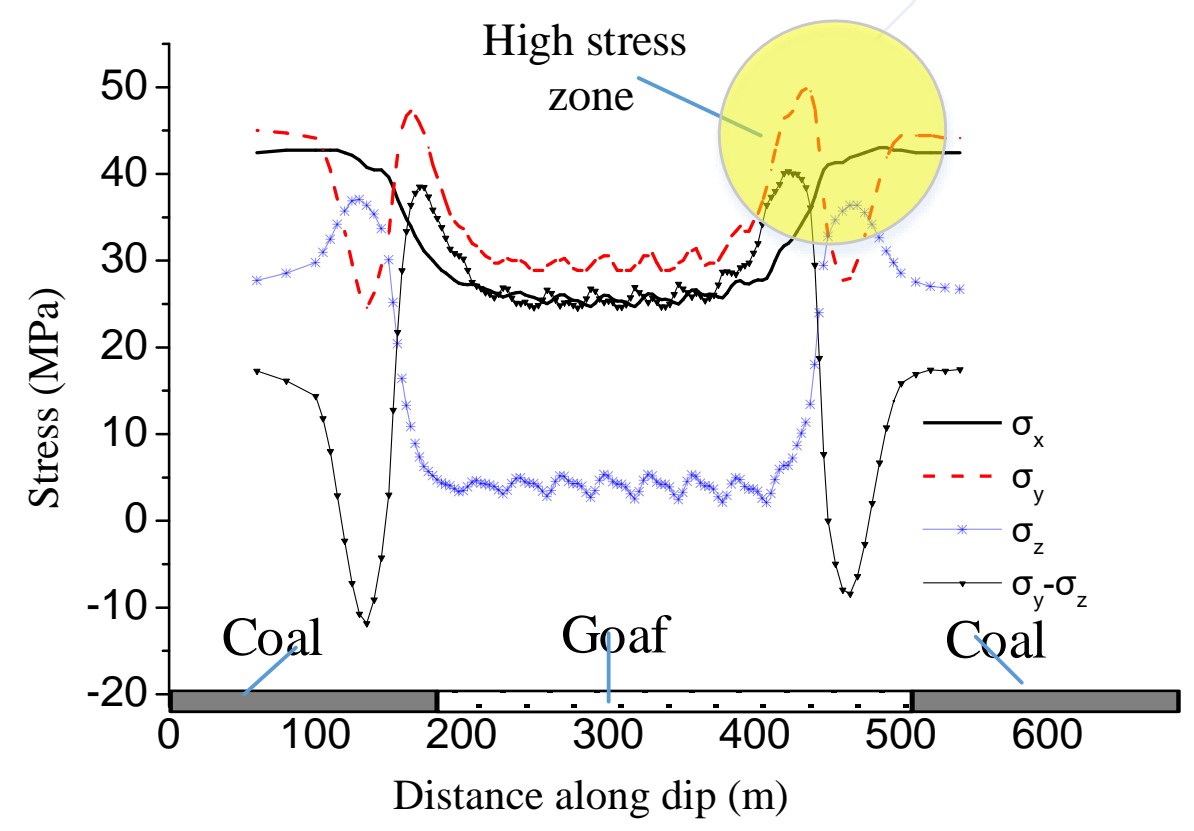

Fig. 7 Stress distribution in the hard floor along the dip

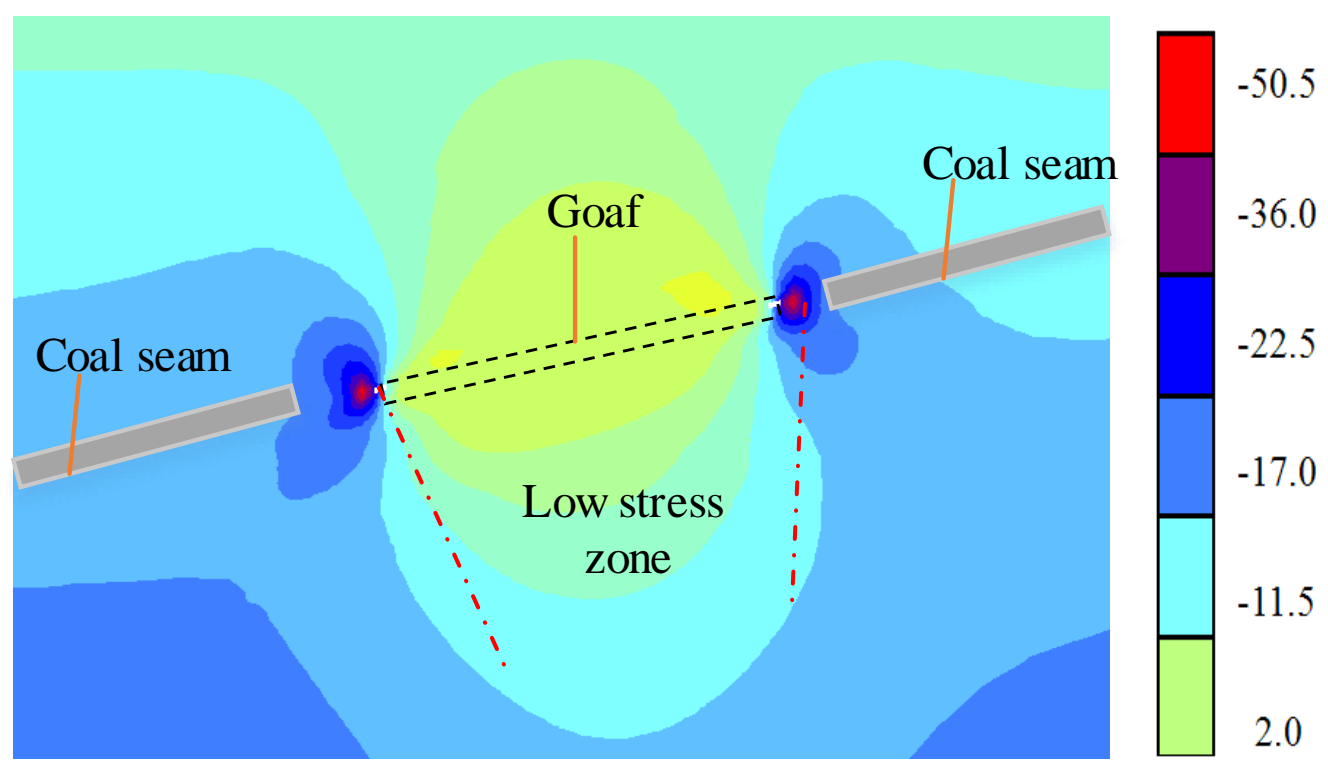

(a) $\sigma_{z}$ 


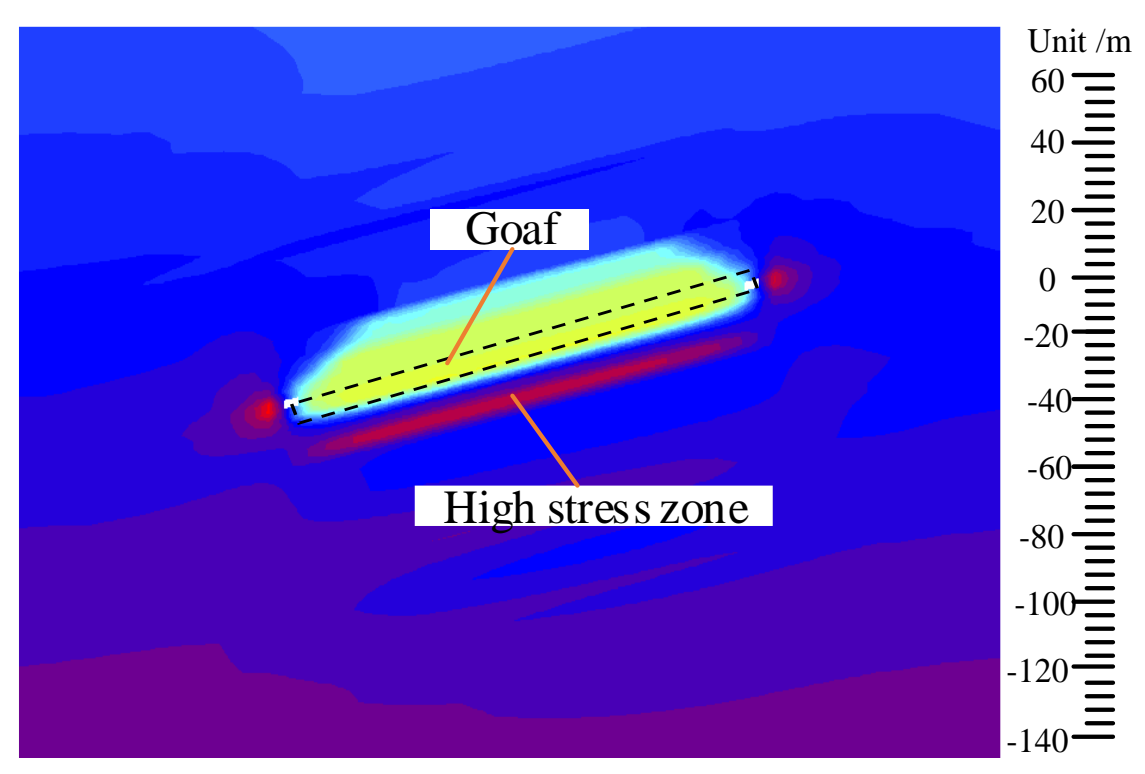

(b) $\sigma_{y}$

Fig. 8 Stress distribution in the stope floor

On the basis of the simulation of similar materials, the 6.24-m-thick fine sandstone in the main roof initially ruptured at an advancing distance of $40 \mathrm{~m}$ in the coal face (Fig. 9(a)). The overlying strata above the caving zone fractured successively and the maximum height of the fissure zone is $11 \mathrm{~m}$. Small heaves developed in the immediate floor. Bed separation formed between the overlying strata at an advancing distance of $80 \mathrm{~m}$. The main roof moved toward the goaf in a stepwise manner. The sphere of influence was $24 \mathrm{~m}$ above the coal seam. The connection of the immediate floor of No. 11 coal was destroyed, accompanied with high-density networked fissures (Fig. 9(b)). The roof fissures extended to the maximum height $(34 \mathrm{~m})$ at an advancing distance of $120 \mathrm{~m}$ and the floor fissures kept on extending. The maximum failure depth of the floor was $14.2 \mathrm{~m}$ (Fig. 9(c)). The bed separation in the overlying strata further intensified, and the height of the fissure zone stabilized at $34 \mathrm{~m}$ (Fig. 9(d)) despite the increase of the coal face due to mining operation. During compaction of the roof caving layer in the goaf, the floor fracture did not expand anymore.

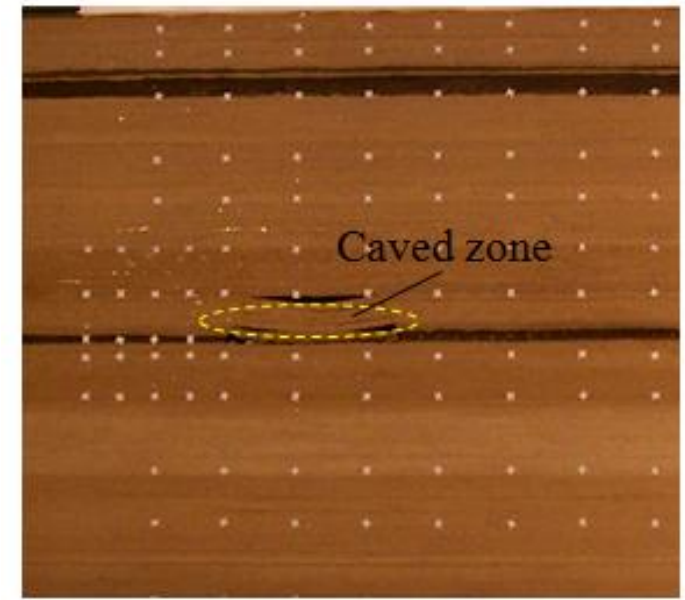

(a) Advancing by $40 \mathrm{~m}$

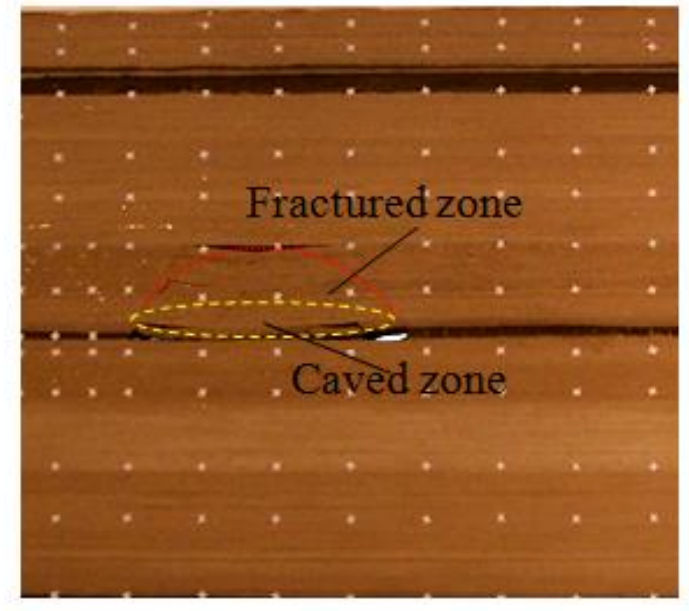

(b) Advancing by $80 \mathrm{~m}$ 


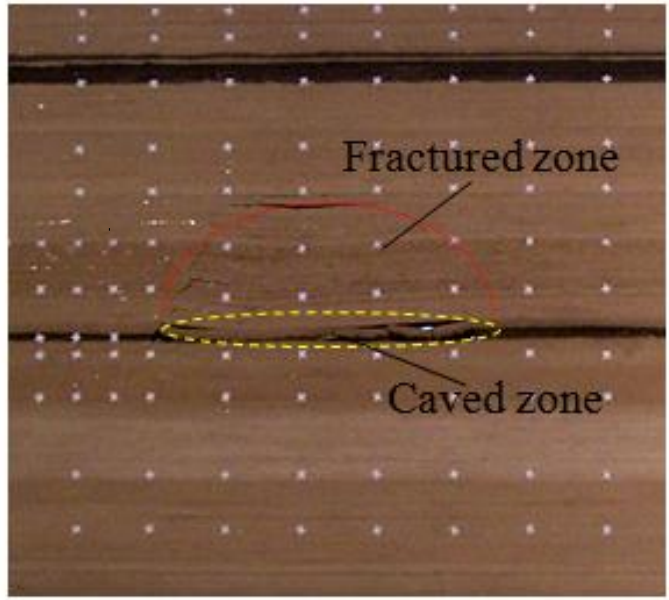

(c) Advancing by $120 \mathrm{~m}$

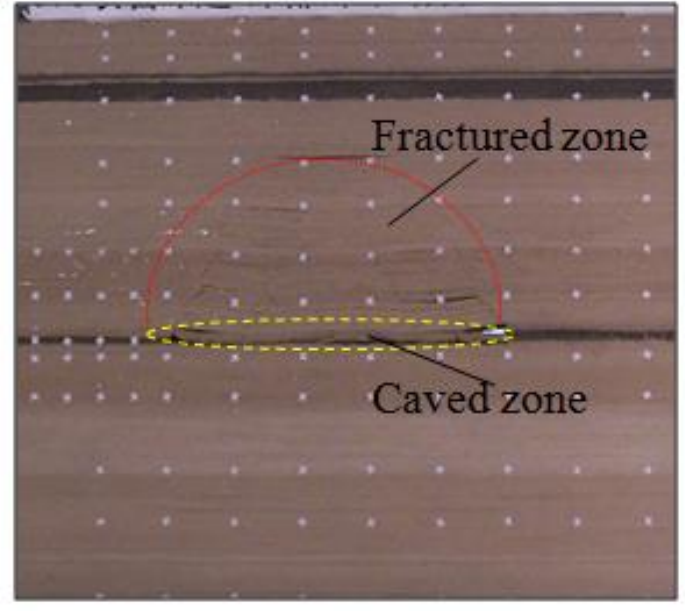

(d) Advancing by $180 \mathrm{~m}$

Fig. 9 Form of rock stratum movement under different advancing distances

Stress in coal seam floor strata in front of the coal face exceeded the limit and kept on increasing after the coal seam was mined (Fig. 10). The 236\# measuring point was in the 1.79-m-thick siltstone which was $13.4 \mathrm{~m}$ below the coal seam. If the points are 40, 30, 22, and $18 \mathrm{~m}$ away from the coal face, then the strains are 13.5, 25.35, 29.06, and 30.16, respectively. However, if the point is less than $18 \mathrm{~m}$ away from the coal face, the strain sharply drops. Delayed unloading occurred when the measuring point enters into the goaf and the unloading range shows an inverted "V shape." If the advancing distance is $200 \mathrm{~m}$, then the strain of the immediate floor at $80 \mathrm{~m}$ behind the coal face is -38.17 , indicating the occurrence of strong tensile stress in the immediate floor. The mechanism was that energy fields in the overlying rocks, coal seam, and floor experience sudden change after coal seam recovery and a considerable proportion of energy is released, resulted in roof settling and floor heaving. This rock stratum is in the floor fissure zone. Meanwhile, given that the overlying stress shell bears the overlying strata, the weight of the overlying strata cannot be completely transferred to the floor strata due to the falling gangues in the goaf, thus generating strong tensile stress in the stope floor rock strata. The variation of stress of the rock strata 19.4, 23.0, 25.0, and $31.8 \mathrm{~m}$ below the coal seam has the advancing distance similar to that of rock stratum $13.4 \mathrm{~m}$ below the coal seam. Stress reduction zone in the floor strata below the goaf has an inverted "V shape." In the advancing process of the working face, the coal seam floor showed an advanced pressurization. Unloading of the floor strata in the goaf was not accomplished instantly. Stress reduced to the minimum after the panel horizontally advances at $60 \mathrm{~m}$, showing typical time effect. Meanwhile, the underlying rock strata in the goaf showed different degrees of tensile stress. The top-down vertical stress below the goaf gradually increased based on the original stress level. 


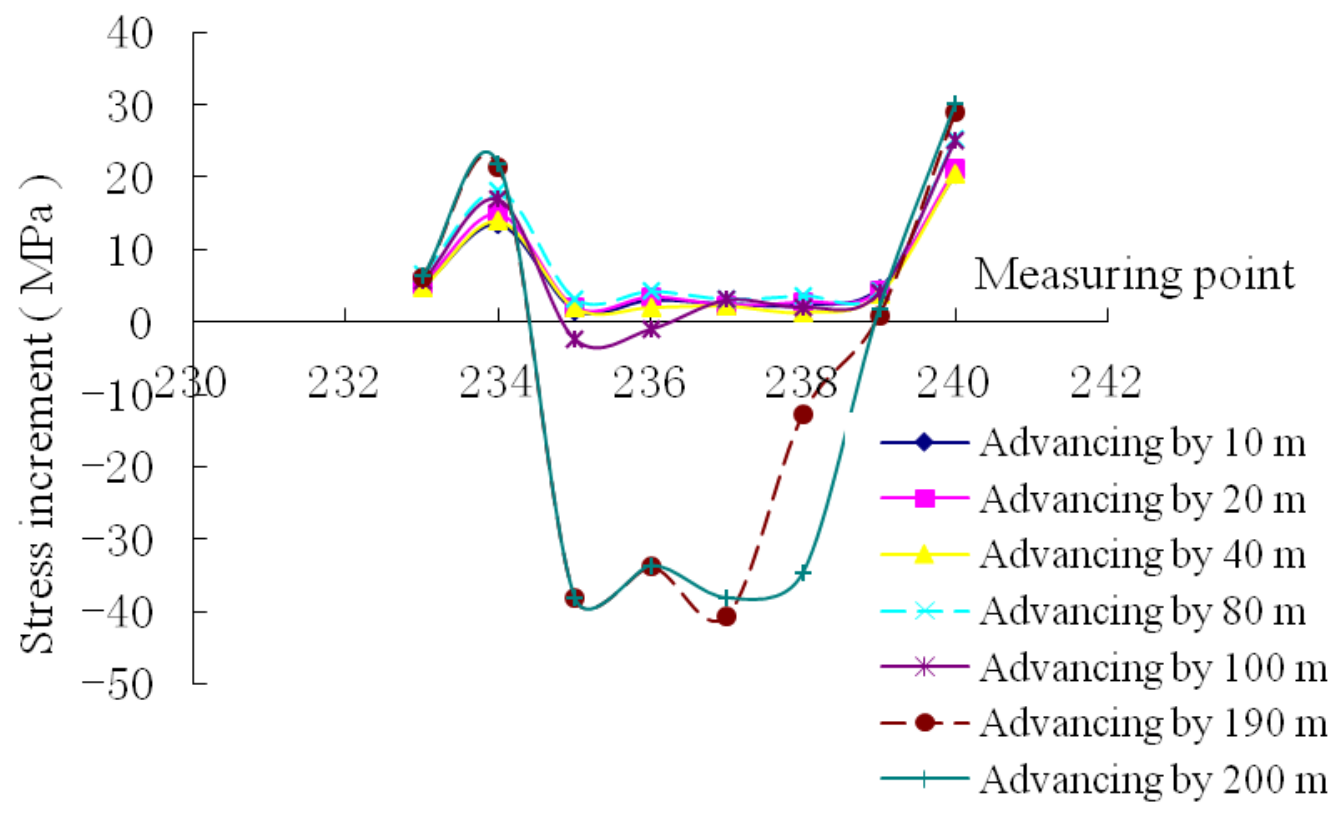

Fig. 10 Relation curves of dependent variables and advancing distance

Fig. 11 shows the dynamic curve of the observed stress in the coal seam of the 66207 panel. On the basis of the observation results, the coal seam stress started to gradually increase when the coal face is 67 $\mathrm{m}$ away from the measuring point, indicating that the sphere of mining influence is about $67 \mathrm{~m}$. When the coal face is $34.5 \mathrm{~m}$ away from the measuring point, the coal seam stress began to sharply increase. Stress reached the peak (14.9 $\mathrm{MPa}$ ) when the coal face is $11.7 \mathrm{~m}$ away from the measuring point. With the continuous advancing of the panel, coal seam stress drops dramatically.

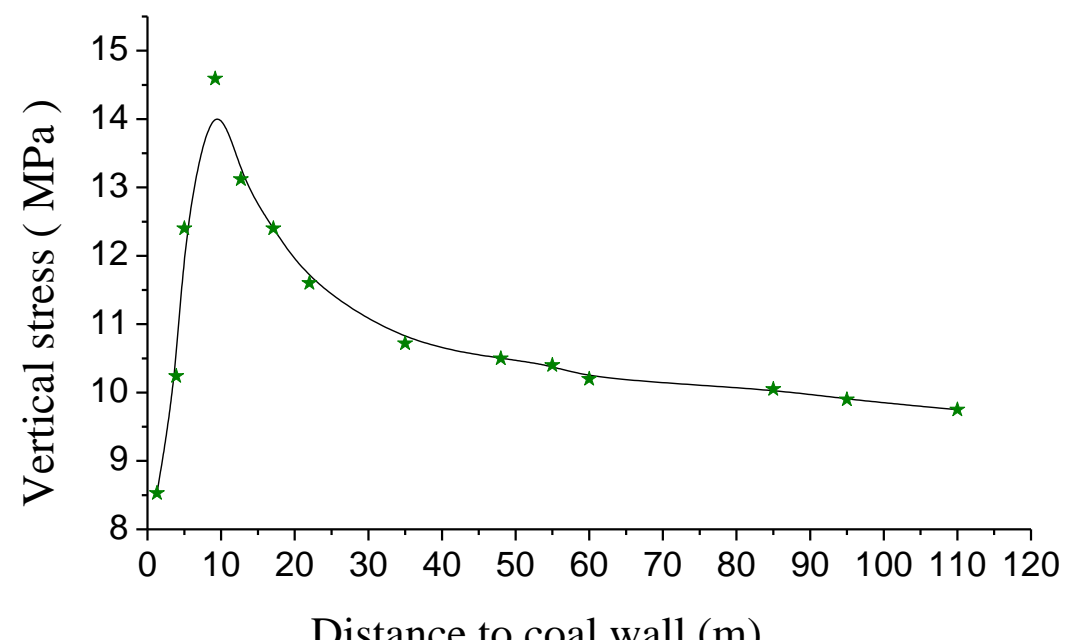

Fig. 11 Variation curve of stress on internal coal seam in the roadway of the 66207 panel

On the basis of the field observation results, stress in the floor (Fig. 12) has an internal correlation with coal seam stress. The peak stress at the measuring point in fine sandstone which was $11.5 \mathrm{~m}$ below the coal seam was $12.4 \mathrm{MPa}$, indicating the low coefficient of supporting pressure concentration than that in the coal seam. However, the peak increased from the coal seam compared with the coal seam stress. The peak stress is $23.8 \mathrm{~m}$ in front of the coal face. The peak stress of sandy mudstone at $23.8 \mathrm{~m}$ below the 
coal seam of the 66207 panel is $10.3 \mathrm{MPa}$. The degree of stress concentration further declined with the peak of $26.1 \mathrm{~m}$ away from the coal face.

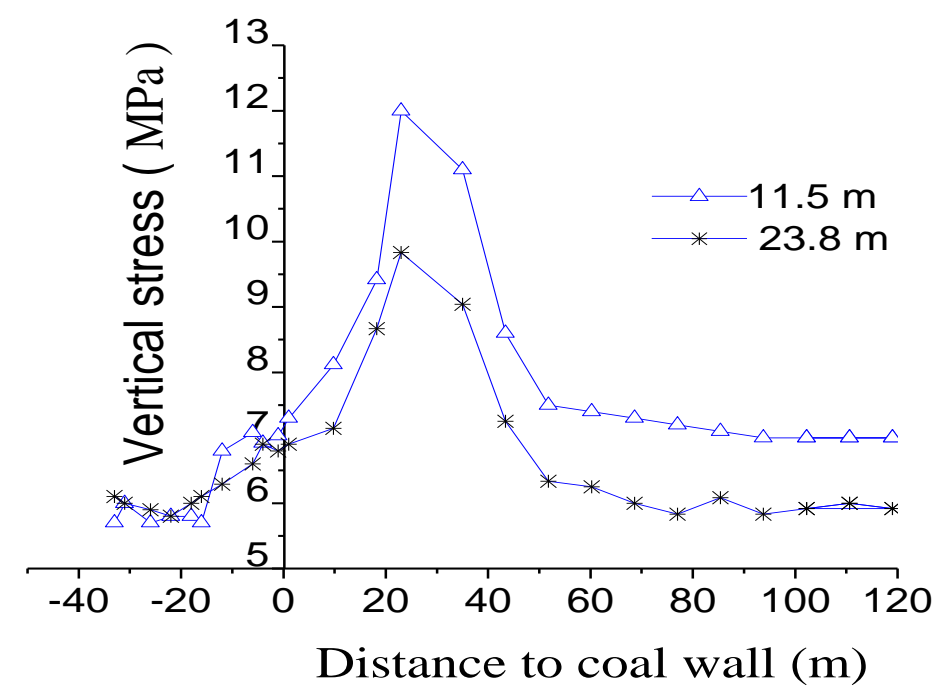

Fig. 12 Variation curve of stress in the underlying strata of No. 7 coal

On the basis of the above analysis, rock stratum stress of the stope floor was basically similar to the variation law of coal seam stress, that is, slow and sharp growth and quick reduction. The only difference was in the degree and position of stress concentration. The higher the vertical distance to the coal seam is, the lower the degree of stratum stress in the stope floor and the further the peak position away from the coal wall will be.

\section{Characteristics of 3D ground-pressure behavior of the stope floor}

\subsection{Deformation characteristics of the unloaded coal seam floor}

Fig. 13 shows the vertical displacement in the panel center gained from numerical simulation after the 66207 panel increased to $200 \mathrm{~m}$. The "incipient point" of the coal seam floor started from the front of the coal face. This rock mass developed compressive deformation on the vertical direction, which clearly caused deformation expansion on the horizontal direction. Thus, rock mass in the expanding zone exerted high squeezing stress to the unloading rock strata below the stope. Moreover, the elastic potential energy in the stope floor after coal seam mining was instantly released. These phenomena resulted in upheavals of the floor in the goaf. The maximum displacement of the immediate floor was $520 \mathrm{~mm}$.

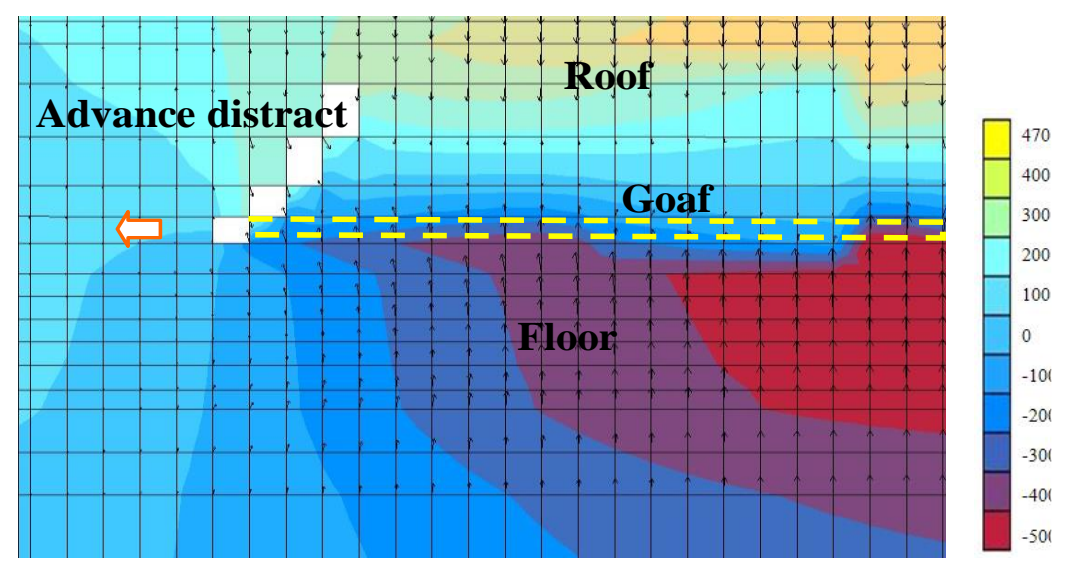

Fig. 13 Vector field of the vertical displacement of the floor on the strike 
The vertical displacement field in the stope floor at different advancing stages of the 66207 panel has the following variation laws. Heaves of the stope floor were generated after the coal seam was mined, which attributed to the collaborative effect of tensile, expanding, and squeezing stress. The isoline of the vertical displacement declined at a uniform rate along the depth. Meanwhile, it may cause slight movement of floor rock strata in front of the coal face. If the length of the longwall panel ranges from $0 \mathrm{~m}$ to $150 \mathrm{~m}$, that is, the length of the advanced longwall panel is smaller than the dip length, then the vertical displacement of the same rock stratum below the goaf gradually increased. After the panel distance increased to more than $150 \mathrm{~m}$, the stratum displacement became increasingly stable with gradual compaction of falling rocks in the goaf. The isoline of the vertical displacement finally represented the "flat pattern."

After the panel distance increased to over $220 \mathrm{~m}$, the isoline of rock stratum movement at different points has similar morphology with the isoline of vertical stress. The displacement of roof rock strata was far higher than that of the coal seam floor. The vertical displacement of the roof and floor was symmetric around the non-mirror image of the coal seam. The maximum displacement of the floor at $95 \mathrm{~m}$ in front of the coal face which was beyond the sphere of critical influence of the shell base was $1.5 \mathrm{~mm}$. The vertical displacement of the rock strata at $10 \mathrm{~m}$ in front of the coal face which was in the sphere of critical influence of the shell base sharply increased. The maximum displacement of the immediate roof was 3.6 $\mathrm{mm}$, and the isoline of the vertical displacement was no longer approximately distributed horizontally. The rock stratum of the immediate roof below the coal seam developed a non-uniform deformation. With the range of 0-55 $\mathrm{m}$ behind the coal face, the displacements of strata in the coal seam floor were higher than that in deep positions. The displacement isoline was distributed uniformly, indicating the absence of large-scale separation layer between the rock strata. The vertical displacement of the rock strata in the same layer was positively related to distance to the coal face. The maximum displacement of the immediate roof increased gradually from $2.1 \mathrm{~cm}$ to $35 \mathrm{~cm}$. At points beyond the range of $55 \mathrm{~m}$ behind the coal face, the depth of the stress shell formed by the surrounding rocks in the stope floor became stable. The main roof in the low-stress zone under the protection of the overlying stress shell gradually fractured. Falling rocks in the immediate roof gradually reached the inner arc roof, thus making activities of floor rock strata increasingly stable. The maximum displacement of the immediate floor is stabilized at $35 \mathrm{~cm}$.

Results of similar materials are consistent with numerical calculation. On the basis of the results of similar materials (Fig. 14), the initial equilibrium of the primary rock stress was gradually destroyed, and the stress field regulated continuously to reach a new equilibrium with the panel advancing. This phenomenon was manifested by regular movement of the rock strata below the goaf. Measuring points below the goaf moved upward to different extents in comparison with the horizontal measuring line, which generated heaves. These heaves were arc in shape with downward opening. The largest heave was in the center of the goaf and the largest heaving volume was $27.6 \mathrm{~cm}$. Moreover, the floor rock strata in front of the coal wall developed compressive deformation. 


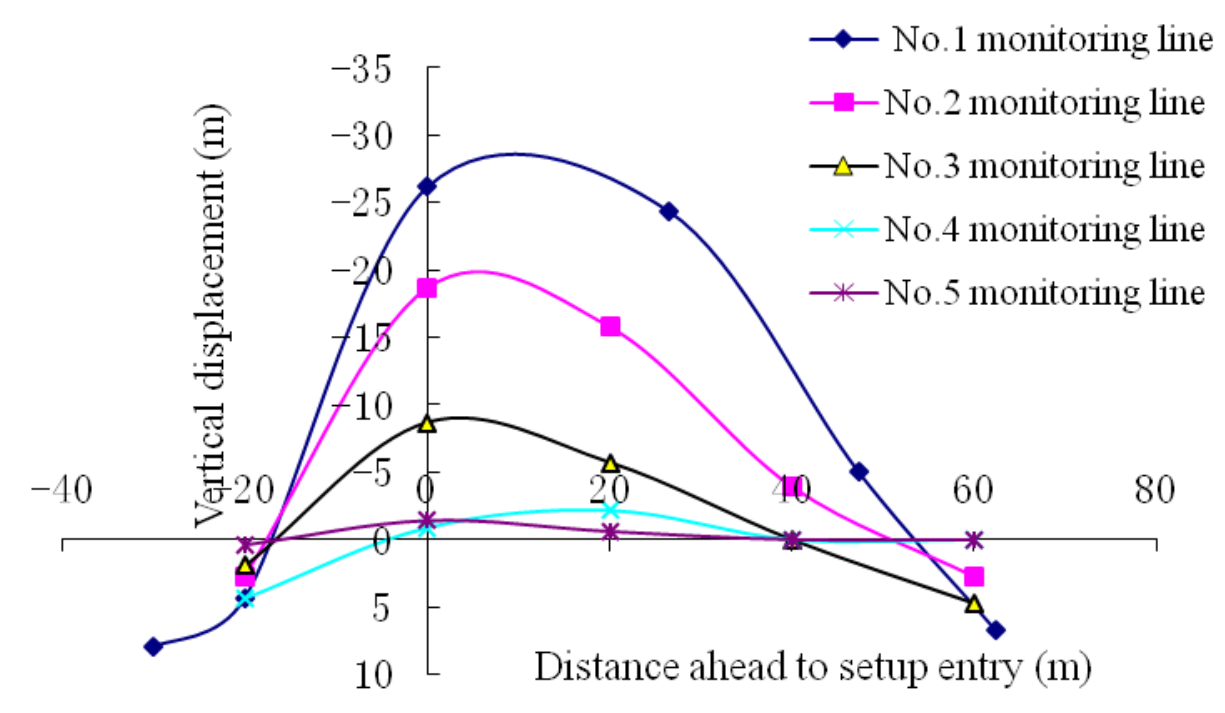

Fig. 12 Vertical displacement curves of the floor strata at an advancing distance of $50 \mathrm{~m}$

\subsection{Plastic failure characteristics of the unloaded coal seam floor}

Fig. 15 shows the distribution of the failure zones in the panel center along the strike when the 66207 panel distance increases to over $200 \mathrm{~m}$. Progressive failure characteristics of strata in the stope floor were observed. When the advancing distance of the panel is shorter than $150 \mathrm{~m}$, the mechanical properties of the strata will deteriorate, the failure zone will gradually expand, and the failure depth will increase with the increase of the advancing distance. When the length of 66207 panel exceeds $150 \mathrm{~m}$, the failure depth of the rock strata in the stope floor will remain unchanged and will be stable at $24.3 \mathrm{~m}$. The strata within $25.6 \mathrm{~m}$ below the goaf were all in yield and failure states. The shallow floor strata in front of the coal face under high supporting pressure of the stress shell base developed increased failure. After the rock mass in this zone enters into the goaf, the failure depth of the surrounding rocks in the stope floor increased to the maximum corresponding to exploiting technological conditions under the combined effect of high tensile stress, expanding stress of deep strata, and horizontal squeezing stress. The shallow strata in the stope floor presented tensile failures and developed vertical fissures under the tensile stress effect. For strata in the protective range of the stress shell in the stope floor, the concentration degree of horizontal and shearing stress was lower than that in the adjacent zone, which was the stress reduction zone, and the expanding stress to the stope is the principal stress. In deep positions, it is manifested as the tensile-shearing composite failure. The morphology of the failure zone was parallel strata, accompanied with shearing fissures with high shearing stress that run through the inclined goaf of the coal face (Fig. 16). The fracture zone extended outside of the coal face. 


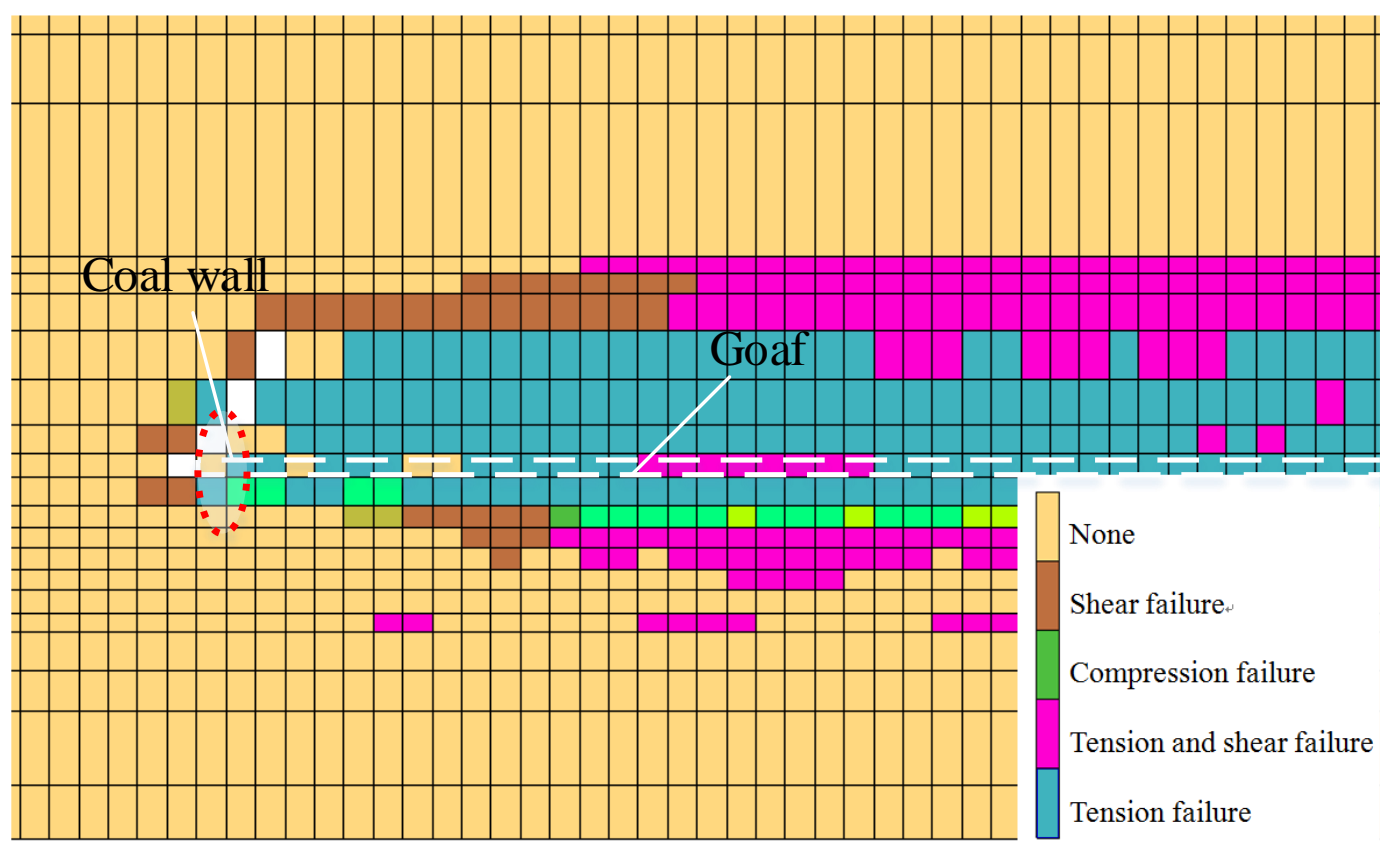

Fig. 15 Distribution of fracture ones of the surrounding rocks on the strike

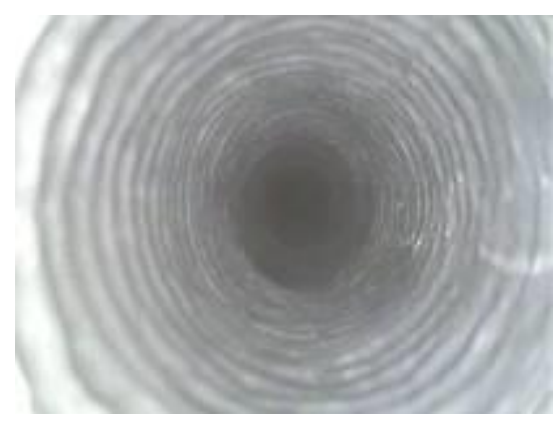

(a) $60 \mathrm{~m}$

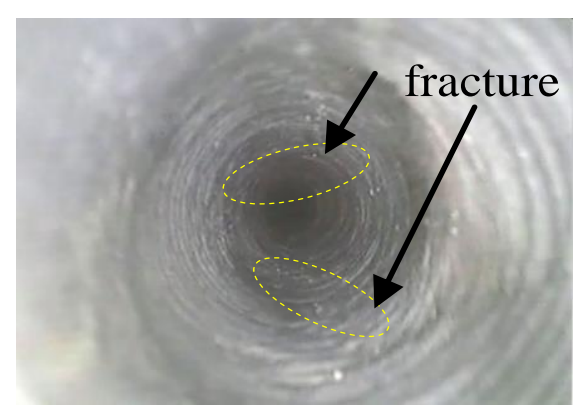

(b) $-40 \mathrm{~m}$

Fig. 16 Endoscopic image of the surrounding rock integrity in the coal seam floor under different advancing distances

\section{Conclusions}

The "mining-induced stress" that forces the surrounding rocks to move toward the mined space is the main cause of critical disasters, including floor water inrush coal and gas and rock burst. Many redistribution forms (e.g., vertical, horizontal, shear, maximum principal, minimum principal, and deviatoric stress) of 3D stress field caused by unloaded disturbance of the surrounding rocks exist. Mechanical behaviors such as deformation and failure of stope floor rock strata are the consequences of the collaborative effect of multiple mechanical parameters. Studying the mechanical efficiency induced by the surrounding rock unloading in deep stope floor may disclose the space-time inoculation mechanism of mining-induced stress field that weakens structural damages of coal rock mass and recognize sensitivity of mechanical parameters to structural damage degree of the surrounding rock. The main factors that influence the mechanical behaviors of strata in the stope floor are proposed in this work. The internal evolution laws of fracture of deep rock mass and mining-induced stress field are analyzed. Results provide theoretical bases for realizing the dynamic control of a disaster-causing environment and for reducing or changing disaster-inducing conditions. The mechanical mechanism of failure of the 
unloaded coal seam floor is further discussed systematically by combining laboratory experiment, field test, and numerical simulation. Several major conclusions are drawn.

(1) The coal seam floor in deep coal mine is viewed simply as a supported rectangular plate under the collaborative effect of uniformly distributed horizontal and uniformly distributed in-plane forces. In addition, the minimum critical yield load is acquired. The mechanical mechanism of plastic buckling failure of the stope floor and the heaving mechanism are revealed.

(2) Influenced by the high stress of the shell of surrounding rocks in the stope floor and deflection of the principal stress, heterogeneity of coal seam stress is observed. The vertical stress is unloaded layer by layer in an up-down manner. The unloading degree of horizontal stress is relatively low. Concentration zones of high horizontal stress in several areas exist. The high squeezing stress and vertical resilience of the strata cause buckling fracture of the coal seam floor. Fractured strata slide along the fracture surface and developed heaves.

(3) Strata in the stope floor show progressive failure characteristics. The stress shell of surrounding rocks in the stope floor of deep longwall panel is a sensitive mechanical parameter to 3D mining pressure. The development law of mining pressure in strata is controlled by the objective existence of stress shell and effects induced by its space-time evolution. The maximum displacement and failure zones in the rock strata of the stope floor are in the low-stress zone on the boundaries of the stress shell.

\section{Acknowledgments}

This research was supported by the National Key Research and Development Program of China (2017YFC0804202) and Anhui Provincial Natural Science Foundation (1808085QE177).

\section{References:}

1. Cook NGW, Hoek E, Pretorius JPG, Ortlepp WD, Salamon MDG. Rock mechanics applied to the study of rockbursts. South African Institute of Mining and Metallurgy.1966; 66(10):435-528.

2. Walsh JB. Energy changes due to mining. International Journal of Rock Mechanics and Mining Sciences and Geomechanics Abstracts.1977; 14(1):25-33.

3. Hoek E, Brown ET. Practical estimates of rock mass strength. International Journal of Rock Mechanics and Mining Sciences.1997; 34(8):1 165-1 186.

4. Aubertin M, Li L, Simon R. A multiaxial stress criterion for short and long-term strength of isotropic rock media.International Journal of Rock Mechanics and Mining Sciences.2000;37(8):1 169-1 193.

5. Li BY. Down three zones in the prediction of the water inrush from coalbed floor Aquifer-theory. Development and Application.Journal of Shandong Institute of Mining and Technology(Natural Science). 1999;8(4):11-18.

6. Wang ZY, Liu HQ. Theory and practice of coal mining Discipline on confined Water. Journal of China Coal Society.1994; 19(1): 40-48.

7. Yuan L. Strategic thinking of simultaneous exploitation of coal and gas in deep mining. Journal of China Coal Society.2016; 41(1):1-6. 
8. Qian MG, Miao XX, Li LJ. Mechanism for the fracture behaviours of main floor in longwall mining. Chinese Journal of Geotechnical Engineering.1995; 17(6):56-61.

9. Miao XX, Chen RH, Bai HB. Fundamental concepts and mechanical analysis of water-resisting key strata in water-preserved mining. Journal of China Coal Society. 2007; 32(6):561-564.

10. Jiang JQ, Feng ZQ, Han JS. Classification of structural stability of surrounding rocks of roadway affected by overhead mining and decision making of support parameters. Chinese Journal of Rock Mechanics and Engineering. 1999; 18(1):81-85.

11. Wang JA, Peng SP, Meng ZP. Fraeture Charaeteristies of Floor Strata due to Double Longwall Mining on Confined Aquifer .Journal of University of Scicnce and Teehnolegy Beijing.2002;24(3):243-247.

12. Wang LG, Han M, Wang .S, Su-Bei OU. Stress distribution and damage law of mining floor. Journal of Mining \& Safety Engineering. 2013;30(3):317-322.

13. Zhang Y, Zhang L, Zhao F. Dynamic evolution rules of mining-induced fractures in different floor area of short-distance coal seams. Journal of China Coal Society. 2015;40(4):786-793.

14. Zhu SY, Ju YJ, Zhao ZZ, Liu DQ. Field measurement study on deformation and destruction of "three-soft" coal seam floor of chaohua coal mine. Chinese Journal of Geotechnical Engineering. 2009; 31(4), 639-642.

15. Wu JW, Fan C. Study on in-situ measurement of water-resisting ability of coal seam floor rock mass. Chinese Journal of Geotechnical Engineering. 2003; 25(1) : 67-70.

16. Feng Q, Jiang BS. Analytic solution for stress and deformation of stope floor based on integral transform . Rock and Soil Mechanics. 2015; 36(12):3482-3488.

17. Xie GX, Wang L. Lithologic effect on the mechanical characteristics of mining-induced stress shell. Journal of China Coal Society. 2013; 38(1):44-49.

18. Li JZ. Study on mechanical characteristics on surrounding rock of stope floor stress shell .Huainan: AnHui University of Science and Technology. 2015.

19. Sun J, Wang LG. Instability mechanics criterion of inclined water-resisting key strata in coal seam floor .Journal of China Coal Society. 2014;39(11): 2276-2285.

20. He FL, Chen DD, Xie SR. The kDL effect on the first fracture of main roof with elastic foundation boundary . Chinese Journal of Rock Mechanics and Engineering. 2017;36(6):1384-1399.

21. Xie GX, Li JZ, Wang L, Tang YZ. Mechanical characteristics and time and space evolvement of stress shell in stope floor stratum. Journal of China Coal Society. 2018;43(1):52-61. 